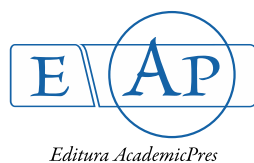

\title{
Effect of Quail Egg Administration on Some Liver Function Related Parameters
}

\author{
Patrick E. ABA \\ University of Nigeria, Nsukka, Enugu State, Department of Veterinary Physiology and Pharmacology, \\ Nigeria; patrick.aba@unn.edu.ng (*correspondingauthor)
}

\begin{abstract}
There are a lot of testimonies on the therapeutic efficacies of quail egg on diabetics and on liver disorders. This study investigated synthetic and conjugatory states of the liver in diabetic rats administered varying concentrations of quail egg solution. Thirty (30) adult male albino Wistar rats were assigned to 5 groups of 6 rats each. Groups 2-5 of rats were injected with alloxan monohydrate intraperitoneally at the dose of $160 \mathrm{mg} / \mathrm{kg}$, while rats in group 1 served as normal control. Upon establishment of fasting blood glucose level above $126 \mathrm{mg} / \mathrm{dl}$, the rats in groups $2-4$ were administered $30,15 \mathrm{and} 7.5 \mathrm{mg} / \mathrm{ml}$ of quail egg solution respectively for 7 days. Rats in groups 1 and 5 received distilled water $(10 \mathrm{ml} / \mathrm{kg})$ each. All treatments were through the oral route. At the end of the 7 days duration of the study, blood samples for serum protein and bilirubin assays were collected. Results indicated that the quail egg administration to alloxanized rats did not alter total serum protein and albumin values, but improved significantly $(\mathrm{p}<0.5)$ the conjugated bilirubin values compared to that of the negative control group (group 5). It was concluded that administration of quail egg solution to alloxanized rats aided hepatic conjugatory ability with little or no effect on its synthetic function.
\end{abstract}

Keywords: diabetes, liver damage markers, quail egg, Wistar rats

\section{Introduction}

Quail egg is a delicacy in many parts of the globe including Europe and North America. In Nigeria, the easterners (Igbos) call the quail egg "Ogazi egg". Quail egg contains several biologically active substances that are required for healthy living. Stadelman (1995) noted that the nutritional value of quail eggs is much more than those offered by other eggs and they are rich sources of antioxidants, minerals and vitamins. Agarwal et al. (2006) equally reported that the quail egg yolks were significantly higher in nutrient in comparison with those of the egg white. According to Dimitrov et al. (2008), the nutritional value of quail egg is 3 to 4 times higher than that of chicken eggs. The most essential fatty acids in quail egg yolk are linoleic acid, docosahexaenoic acid and arachidonic acid (Kostova et al., 1993).

Alloxan has been reported to be toxic to pancreatic beta cells. Researchers have reported that alloxan, through a redox reaction generates free radicals which destroy cells including the pancreatic beta cells (Szukudelski, 2001). It has been reported that antioxidants play vital roles in ameliorating diseases and conditions associated with free radical productions such as diabetes (Kaeler et al., 1993). The negative effects of alloxan monohydrate on various tissues and organs such as liver cannot be overemphasized (El-Dermardash et al., 2005; Adesokan et al., 2009). The liver is saddled with numerous functions including synthetic (such as protein synthesis) and conjugatory (like bilirubin conjugation). In cases of liver disorder, these functions may be impaired (Murray, 2000).

The objective of this study is to assess the state of the function of liver of diabetic rats given quail egg solution using protein and bilirubin assays as markers.

\section{Materials and Methods}

Animals

Adult male albino Wistar rats of 10 to 16 weeks and average weight of $160 \pm 15 \mathrm{~g}$ were obtained from the animal house of the Faculty of Biological Sciences, University of Nigeria, Nsukka, Enugu state, Nigeria. The animals were acclimatized for the duration of 7 days under standard environmental conditions with a $12 \mathrm{~h}$ light/dark cycle maintained on a regular feed $\left(\mathrm{Vital}^{\odot}\right.$ feed) and water ad libitum. The experimental protocol used in this study was approved by the ethics committee of the University of Nigeria, Nsukka and conforms with the guide to the care and use of animals in research and teaching of University of Nigeria, Enugu state, Nigeria.

\section{Quailegg}

Quail eggs used were obtained from the Faculty of Veterinary Medicine, University of Nigeria, Nsukka, Enugu state, Nigeria Farm. The freshly laid eggs weighed between $10-15 \mathrm{~g}$. 
150

\section{Experimental design}

Thirty adult male albino Wistar rats were assigned into 5 groups of 6 rats per group. Following establishment of diabetes mellitus on the 2 nd day post induction, the rats

Table 1. Administration of varying concentrations of quail egg solution to Wistar rats

\begin{tabular}{cc}
\hline Group & Treatment \\
\hline 1 & $\begin{array}{c}\text { Non diabetic rats administered } 10 \mathrm{ml} / \mathrm{kg} \text { distilled water } \\
\text { (Normal control) }\end{array}$ \\
2 & $\begin{array}{c}\text { Diabetic rats administered } 30 \mathrm{mg} / \mathrm{ml} \text { quail egg solution } \\
\text { (Highest concentration) }\end{array}$ \\
3 & $\begin{array}{c}\text { Diabetic rats administered } 15 \mathrm{mg} / \mathrm{ml} \text { quail egg solution } \\
\text { (Medium concentration) }\end{array}$ \\
5 & $\begin{array}{c}\text { Diabetic rats administered } 7.5 \mathrm{mg} / \mathrm{ml} \text { quail egg solution } \\
\text { (Lowest concentration) }\end{array}$ \\
\hline
\end{tabular}

were treated orally and daily with different concentrations of quail egg solution as follows:

Upon establishment of diabetes, the quail egg solution was administered daily through the oral route for 7 days. Blood samples for assay of some biochemical parameters were collected on day 7 post treatment.

\section{Preparation of quail egg}

An empty beaker was weighed (A g). The shells of the quail eggs were broken with spatula and the contents emptied into the beaker. The weight of the beaker and the contents were recorded as B g. The weight of the contents of the egg alone was obtained by subtracting the weight of the beaker alone from the weight of the beaker and its contents. Thus the weight of the egg yolk and albumen, C (g) was expressed mathematically thus:

$\mathrm{C}(\mathrm{g})=\mathrm{B}(\mathrm{g})-\mathrm{A}(\mathrm{g})$

C (g) was solubilized in a calculated quantity of distilled water to make a desired concentration of quail egg solution and thereafter, serial dilutions of the stock solution were made for the different groups.

\section{Induction of experimental diabetes mellitus}

Diabetes was induced in rats using the method described by (Venugopal et al., 1998). The rats were fasted for $16 \mathrm{~h}$ prior to induction of diabetes. Diabetes was induced by single intraperitoneal injection of alloxan monohydrate at the dose of $160 \mathrm{mg} / \mathrm{kg}$. Diabetes was established on day 2 post induction on confirmation of fasting blood glucose (FBG) levels above $7 \mathrm{mmol} / \mathrm{l}$ or $126 \mathrm{mg} / \mathrm{dl}$.

\section{Blood collection}

Blood samples were collected from the animals into a clean bottle using orbital technique. The blood samples were allowed to clot then centrifuged and the sera harvested for biochemical determinations. Blood samples were collected from the retrobulbar plexus of the median canthus of the eye of the rats.

\section{Serum biochemistry determinations}

The clotted blood meant for serum biochemistry was separated from clear serum by centrifugation. All serum biochemistry determinations were carried out following standard procedures, using Randox test kits (Randox, United Kingdom).

\section{Determination of serum total and conjugated bilirubin}

Both total and conjugated serum bilirubin were determined following the Jendrassik-Grof method (Doumas et al., 1973) for the in vitro determination of direct and total bilirubin in serum using the bilirubin test kit.

\section{Determination of total proteins}

Total proteins were determined by the direct Biuret method (Tietz, 1975), for the in vitro determination of total proteins in serum or plasma using the total proteins test kit.

\section{Determination of serum albumin}

The serum albumin was determined by the bromocresol green method (Doumas et al., 1971), for the in vitro determination of albumin in serum or plasma using albumin test kit.

\section{Statistical analyses}

Data obtained were analyzed using One-way Analysis of Variance (ANOVA). Variant means were separated using Duncans multiple range post hoc test. Results were presented as Mean \pm Standard Error of the Mean (Mean \pm SEM).

\section{Results}

Effects of administration of graded concentrations of quail egg on total bilirubin levels of alloxanized rats

The results indicated that the mean serum total bilirubin levels of all the rats' groups did not vary significantly at the end of the experiment when compared with the control (Fig. 1).

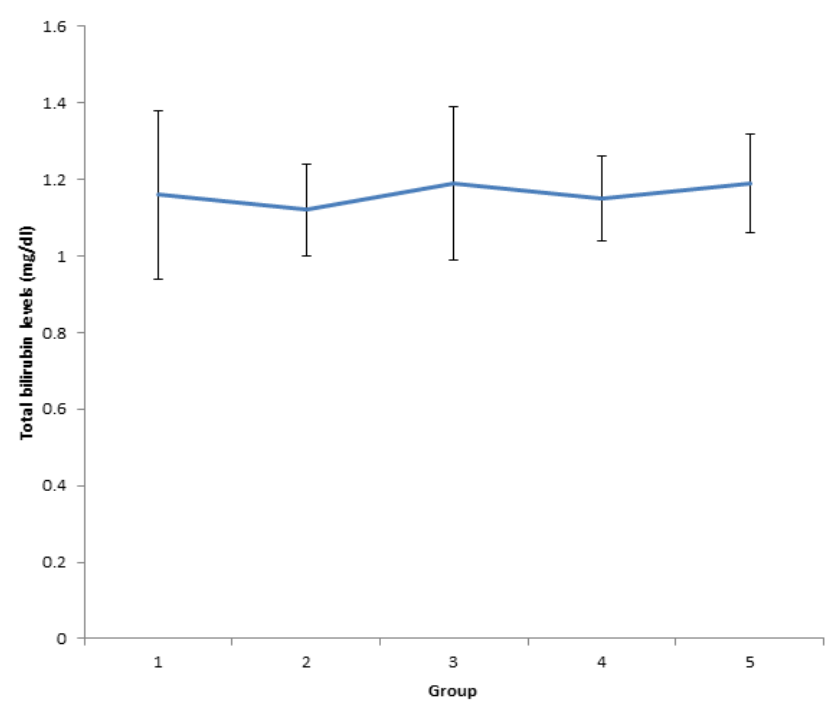

Fig. 1. Effects of administration of graded concentrations of quail egg on total bilirubin levels of alloxanized rats 


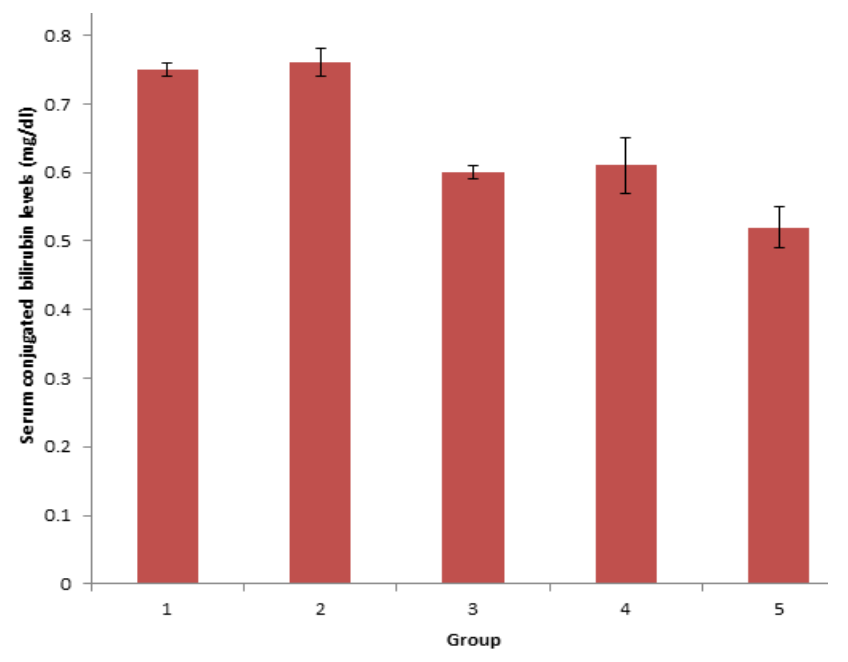

Fig. 2. Conjugated bilirubin values of alloxanized rats treated with varying concentrations of quail egg solution

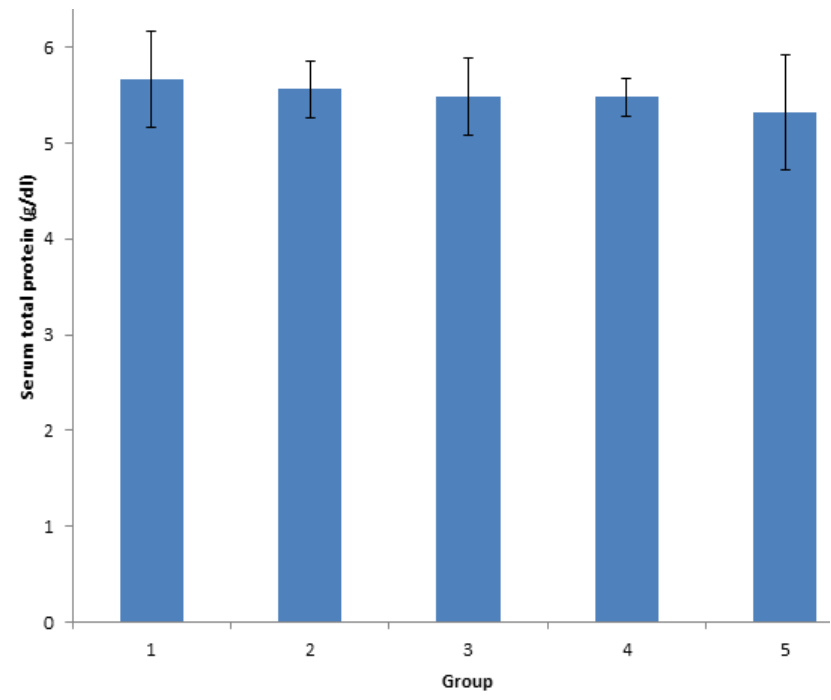

Fig. 3. Effects of administration of varying concentrations of quail egg solution on the serum total protein of alloxanized rats

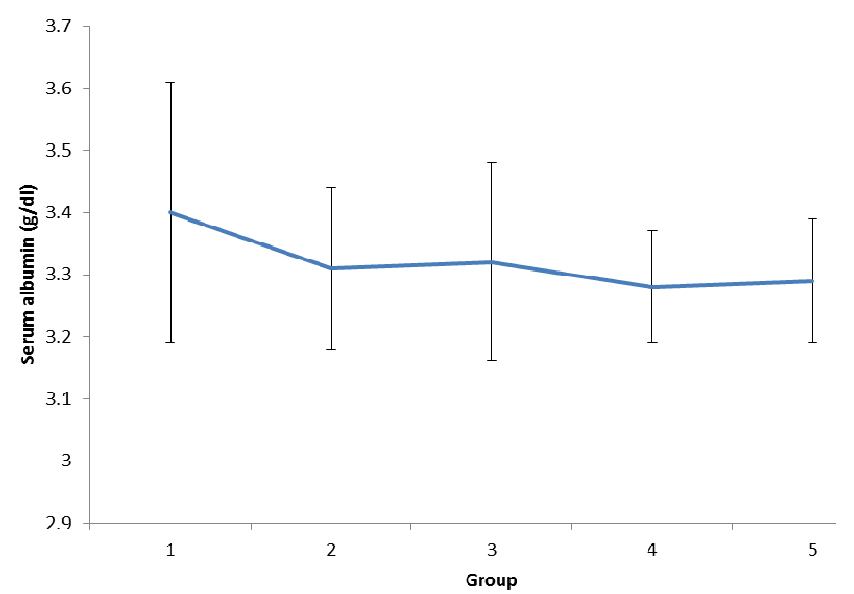

Fig. 4. Effects of quail egg on the serum levels of albumin of alloxanized rats
Conjugated bilirubin values of alloxanized rats treated with varying concentrations of quail egg solution

The serum conjugated bilirubin levels of rats in groups 1 and 2 were significantly $(p<0.05)$ elevated when compared with that of the groups 5 (negative control group), 3 and 4 . The values of the conjugated bilirubin of the groups 3 and 4 rats were comparable (Fig. 2).

Effects of administration of varying concentrations of quail egg solution on the serum total protein of alloxanized rats

The results indicate that there was no significant $(p>0.05)$ difference among all the treated groups when compared to the control (Fig. 3).

Effects of quail egg on the serum levels of albumin of alloxanized rats

The results indicate that there was no observed significant difference among all the treated groups when compared to the control (Fig. 4).

\section{Discussion}

This study evaluated the effect of administering quail egg to alloxan-induced diabetic rats on hepatic function of such rats by assaying bilirubin and protein values.

There were no observed significant changes in the serum levels of total bilirubin among all the groups across the treatment period. However, the increases in the conjugated bilirubin levels of the treated rats compared to the untreated rats indicate a superior hepatic function in the former compared to the later. Hepatic processing of bilirubin is achieved by hepatocytes. However, when there is hepatic injury, such function of the liver as bilirubin processing is impaired (Murray, 2000). It is suggested that treatment with quail egg solution may have improved the alloxaninduced liver injury possibly by mopping free radicals which have been incriminated in the alloxan-mediated tissue injuries (Szukudelski, 2001).

The total protein and albumin levels of both treated and untreated rats were statistically comparable. This can only imply that the damage to the liver may not have taken a chronic course as to impair the protein synthetic function of the liver. Researchers have reported that such functions like protein production can be affected in the cases of chronic hepatic impairment (Mezey, 1982). The plasma half-life of plasma proteins is 2-3 weeks.

\section{Conclusions}

In conclusion, quail egg administration to the alloxanized rats had no effect on total protein and albumin, but improved the levels of conjugated bilirubin. In general, quail egg administration especially at the concentration of $30 \mathrm{mg} / \mathrm{ml}$ improved hepatic conjugator function.

\section{References}

Adesokan AA, Oyewole OI, Turray BM (2009). Kidney and liver function parameters in alloxan-induced diabetic rats treated with Aloe barbadensis juice extract. Sierra Leone Journal of Biomedical Research 1(1):33-37. 
Agarwal SK, Bhanja SK, Majumdar S (2006). Effect of cage floor space on the egg production performance of Japanese quail (Coturnix coturnix japonica) during winter. Indian Journal of Poultry Science 41(2):205-207.

Dimitrov G, Bakalivanora T, Grigorov S (2008). Fatty acid content of egg yolk in Bovans Brown stock layers before and after moulting. Poultry Husbandry 5(2):10-12.

Doumas BT, Perry BW, Sasse EA (1973). Standardization in bilirubin assays: evaluation of selection methods and stability of bilirubin solutions. Clinical Chemistry 19(9):984-993.

El -Dermardash FM, Yousy MV, EL-waga NIA (2005). Biochemical study on the hypogycaemic effects of onion and garlic in alloxaninduced diabetic rats. Food and Chemical Toxicology 43(1):57-63.

Kaehler W, Kukliinski B, Ruehlmann C (1993). Diabetes mellitus- a free radical-associated disease. Results of adjuvant antioxidant supplementation. Zeitschrift fur die Gesamte Innere Medizin 48 (5):223-232.

Kostova Z, Gerzilov V, Kutserv T (1993). Morphological characteristics and chemical composition of Japanese quail eggs. Higher Institute of Agriculture Science and Works 38 (3):193-196.
Mezey E (1982). Liver disease and protein need. Annual Review of Nutrition 2:21-51.

Murray RK (2000). Porphyrins and Bile Pigment: In metabolism of proteins and amino acids. Harpers Biochemistry ( $25^{\text {th }}$ edition). Mc Graw-Hill Publishers pp 359-374.

Stadelman W (1995). Egg science and technology. New York: Haworth Press.

Szkudelski T (2001). The mechanism of alloxan and streptozoticin action in beta cells of the rat pancreas. Physiological Research 56(6):537-546.

Tietz NW (1995). Clincal guide to laboratory tests. $3^{\text {rd }}$ edition. WB Saunders Company, Philadelphia pp 518-519.

Venogopal PM, Prince PSM, Pari L (1998). Hypoglycemic activities of Syzigium cumini seeds effect on lipid peroxidation in alloxan diabetic rats. Journal of Ethnopharmacology 61:1-7. 